\title{
THE PRECAMBRIAN HISTORY OF THE ORIGIN AND EVOLUTION OF THE SOLAR SYSTEM AND EARTH. PART 1
}

\author{
M. I. Kuz'min
}

\author{
A.P. Vinogradov Institute of geochemistry of SB RAS, Irkutsk, Russia
}

\begin{abstract}
The paper provides a review of early stages of development the Solar System and the geological history of Earth with reference to the latest data on the origin of the Solar System and the formation of the first continental rocks and results of studies of zircon, the oldest mineral so far dated on Earth. The formation of the Solar System from a gas-and-dust nebula is estimated to have begun 4.568 billion years ago. Ice was formed 1.5 million years later; it concentrated at the periphery of the system and served as the material for the largest planets, Jupiter and Saturn. In the central areas of the system, asteroids with diameters of about $10 \mathrm{~km}$ were formed. Their small bodies were composed of the basic material of the solar nebula, as evidenced by carbonaceous chondrite, CI, which composition is similar to the composition of the Sun, with the exception of hydrogen, helium, and volatile components that served as the main material for peripheral planets of the Solar System. Due to collision and partial merger of such small bodies, the formation of embryos of the terrestrial planets was initiated. Gravity made such embryos to cluster into larger bodies. After 7 million years, large asteroids and planet Mars were formed. It took 11 million years to form Planet Earth with a mass of $63 \%$, and 30 million years to form $93 \%$ of its mass.

Almost from the beginning of the formation of the Earth, short-lived radionuclides, ${ }^{26} \mathrm{Al}$ and ${ }^{60} \mathrm{Fe}$, caused warming up of the small planetary bodies which led to the formation of their cores. During the initial stages, small magma reservoirs were formed, and molten iron particles gathered in the centres of the planetary bodies. As suggested by the ratio of ${ }^{182} \mathrm{~W} /{ }^{184} \mathrm{~W}$, the major part of the core was formed within 20 million years, while its full mass accumulated completely within the next 50 million years.

In 30-40 million years after the creation of the Solar System, the Earth collided with a cosmic body which mass was close to the mass of Mars, and it was the beginning of the formation of its satellite, Moon.

When the Earth - Moon system was subject to the major meteorite bombardment 4.5-4.1 billion years ago, zircons formed due to impact activity on the Moon, and on Earth it caused major eruption of basaltic magma, the differentiation of which led to the formation of acid magmas in small amounts which caused the formation of zircons, the only remnants of the first continental rocks of Earth. Later on, meteorite bombardment continued and contributed to the burial of the first continental acid and basic rocks in the mantle, wherein such rocks eventually became part of the mantle which became the progenitor of granite-greenstone rock associations. Grey gneisses contain traces of the first continental formations of Earth as evidenced by ancient zircons that are ubiquitous in the crust of Earth. The above is confirmed by results of detailed studies of regional zircons with the use of modern analytical equipment providing for high accuracy of local analyses.
\end{abstract}

Key words: mantle, zircons, differentiation, recycling, depleted, lithophilic, siderophilic, volatile components.

Recommended by S.I. Sherman

Citation: Kuz'min M.I. 2014. The Precambrian history of the origin and evolution of the Solar System and Earth. Part 1. Geodynamics \& Tectonophysics 5 (3), 625-640. doi:10.5800/GT-2014-5-3-0146.

\section{ДОКЕМБРИЙСКАЯ ИСТОРИЯ ЗАРОЖДЕНИЯ И ЭВОЛЮЦИИ СОЛНЕЧНОЙ СИСТЕМЫ И ЗЕМЛИ. СТАТЬЯ I}

\section{М. И. Кузьмин}

\author{
Институт геохимии им. А.П. Виноградова СО РАН, Иркутск, Россия
}

Аннотащия: На основе последних данных по формированию Солнечной системы и образованию первых континентальных пород, исследований оставшихся от этих пород обломков цирконов сделан обзор ранних этапов образова- 
ния Солнечной системы и геологической истории Земли. Начало формирования Солнечной системы из пылевой и газовой туманности датируется 4568 млн лет назад. Через полтора миллиона лет сформировался лед, который был сконцентрирован на периферии системы и послужил материалом для образования самых крупных планет - Сатурна и Юпитера. А в центральных частях системы зарождались малые тела, астероиды с диаметром порядка 10 км, сложенные основным веществом солнечной туманности, которое зафиксировано в углистых хондритах CI, состав которых соответствует составу Солнца, кроме водорода, гелия и летучих компонентов, послуживших основным материалом для периферийных планет Солнечной системы. Коллизия малых тел, которые сталкивались и частично соединялись, дала начало формированию эмбрионов планет земного типа. В дальнейшем эти эмбрионы, благодаря гравитации, начали группироваться в более крупные тела. Большие астероиды и планета Марс сформировались через 7 млн лет, Земля, с массой 63 \%, была образована через 11 млн лет, а 93 \% ее массы сформировалось через 30 млн лет.

Почти с начала формирования Земли, благодаря короткоживущим радионуклидам $\left({ }^{26} \mathrm{Al} ;{ }^{60} \mathrm{Fe}\right)$, происходило разогревание малых планетных тел и формирование ядер этих тел. На начальных этапах образовывались малые магматические бассейны и частицы расплавленного железа собирались в центре планетных тел. Судя по соотношению ${ }^{182} \mathrm{~W} /{ }^{184} \mathrm{~W}$ большая часть ядра сформировалась уже через 20 млн лет, но его окончательная масса накопилась за последующие 50 млн лет.

Через 30-40 млн лет после начала создания Солнечной системы произошло столкновение Земли с космическим телом массой, близкой к массе Марса; это послужило началом образования ее спутника Луны.

4.5-4.1 млрд лет тому назад крупная метеоритная бомбардировка, захватившая систему Земля - Луна, привела к образованию цирконов под действием импактов на Луне, а на Земле она вызвала большие извержения основных базальтовых магм, дифференциация которых приводила к образованию малых объемов кислых магм, послуживших причиной образования цирконов - единственных остатков этих первых континентальных пород Земли. В дальнейшем продолжающиеся метеоритные бомбардировки способствовали захоронению первых континентальных кислых и основных пород в мантии, где они в дальнейшем стали частью мантии, которая стала прародителем гранитзеленокаменных ассоциаций пород. В серых гнейсах сохранились следы первых континентальных образований Земли, что зафиксировано в древних цирконах многочисленных зон. Это удалось доказать благодаря детальным исследованиям зональных цирконов с использованием современного аналитического оборудования, способного делать локальные анализы с высокой точностью.

Ключевые слова: мантия, цирконы, дифференциация, рециклинг, деплетированные, литофильные, сидерофильные, летучие компоненты.

\section{1. ВВЕДЕНИЕ}

Ранее казалось, что изучая процессы, определяющие развитие нашей планеты, в локальном районе на ограниченном временном интервале, можно решить все вопросы развития различных структур Земли. С появлением концепции тектоники плит стало понятно, что мы должны более внимательно относиться к латеральным взаимоотношениям одновозрастных различных тектонических, магматических и гидротермальных структур и систем [Zonenshain et al., 1976, 1990]. Однако с появлением интереса к глубинной геодинамике, и особенно к возникновению долгоживущих горячих мантийных полей или областей мантии с повышенными скоростями поверхностных волн, возникла необходимость изучить развитие отдельных крупных структур Земли, их связь с глубинными мантийными процессами [Zonenshain, Kuz'min, 1983; Maruyama et al., 1994, 2007; Dziewonski, 1984; Zhao, 2001; Kuzmin et al., 2010]. Стало ясно, если не понять эволюцию Земли с самых ранних этапов формирования отдельных оболочек нашей планеты и континентальной коры в целом, то трудно определить, где сосредоточены основные запасы полезных ископаемых, как происходило и будет происходить образование самых раз- нообразных структурных элементов и широкого спектра магматических пород. В последнее время, с успехами астрофизики, с пониманием процессов зарождения Солнечной системы, планет земной группы и особенно Земли, можно ответить на многие вопросы об эволюции нашей планеты, которые определяют большинство проблем, связанных с возникновением и развитием ее поверхностных структур. Появились детальные работы по начальным этапам развития Солнечной системы [Wood, 2011; Lauretta, 2011; Wood et al., 2006; Wood, Halliday, 2010], в которых подробно рассматриваются вопросы становления и эволюции Солнечной системы, процессы образования планет земной группы и особенно Земли, сегрегации ядра Земли, образования Луны, формирования минералов мантии и др. Большое значение имело открытие в 80-х годах прошлого столетия [Compston, Pidgeon, 1986] цирконов с возрастом 4376 млн лет, а также оценка условий состояния Земли во время появления первых пород континентальной коры. Все это позволяет сделать обзор процессов ранних этапов как становления Солнечной системы, так и начала становления Земли как планеты. С другой стороны, рассмотрение этих проблем позволяет провести оценку формирования поверхностных и глубинных оболочек Земли, изучить 
работу мантии Земли в более поздние геологические эпохи и ее воздействие на формирование поверхностных структур, магматических пород и руд [Yarmolyuk, Kuzmin, 2012]. Рассмотрению этих проблем посвящена настоящая статья, которая во многом представляет собой обзор последних данных о ранних этапах развития нашей планеты.

В связи с большим количеством фактического материала, который необходимо осветить в данном сообщении, было решено сделать две статьи. В представленной работе рассмотрены вопросы, связанные с формированием Солнечной системы и Земли, а также с появлением первой континентальной коры на Земле.

\section{2. ХАОТИЧНЫЙ И ГАДЕНСКИЙ ЭОНЫ ГЕОЛОГИЧЕСКОЙ ИСТОРИИ}

В работе [Goldblatt et al., 2010] предлагается выделить Хаотичный эон, который охватывает время от образования Солнечной системы до образования планеты Земля и формирования Луны, т.е. системы Луна Земля, и отделить его от последующего, эона называемого Гаденским, который отличается относительным порядком в формировании внутренней структуры нашей планеты.

\section{1. ХАОТИЧНЫЙ ЭОН}

Формирование Солнечной системы началось из пылегазового диска (туманности) 4568 млн лет назад. Окончательное образование Земли произошло примерно, через 100-150 млн лет [Wood, 2011]. Внутри этого эона имеются временные события, которые в настоящее время известны, хотя не однозначны в абсолютном исчислении [Goldblatt et al., 2010]. Однако, благодаря ряду работ, особенности этих событий, их абсолютная геохронология частично могут быть установлены, так как они важны для понимания дальнейшей эволюции Земли. Этот эон имеет уже установленные временные ограничения, как в целом, так и по времени отдельных важных событий внутри него.
Большое значение для установления геохронологии ранних этапов развития Солнечной системы и Земли имеет время существования короткоживущих изотопов Солнечной системы (таблица).

Начало формирования как самого Солнца, так и планет Солнечной системы связано с протосолнечной туманностью, которая состояла из твердых частиц («пыли») и газа. Этот процесс под влиянием гравитационного сжатия привел к образованию сгущения космического материала и преобразованию его в молодые звезды типа Солнца [Khain, 2003]. Вокруг молодых звезд образовывались протопланетные диски - основа зарождения будущих планет. Возможно, состав солнечной туманности, как и таких туманностей у молодых звезд, связан с большим взрывом, благодаря которому за счет ядерных реакций зародились разнообразные химические элементы [Khain, 2003; Lauretta, 2011].

Масса Солнца составляет 99 \% массы Солнечной системы. Состав Солнца корреспондируется с составом космической туманности, из которой вся эта система образовалась. Подтверждением этого являются аналогичные, сопоставимые с Солнцем, ближайшие звезды, состав которых отвечает протозвездной туманности. В протопланетном диске происходило зарождение планетезималей, астероидов и малых тел, в частности метеоритов. Важно подчеркнуть, что углистые хондриты CI имеют состав, отвечающий составу Солнца, за исключением водорода и гелия, т.е. они наиболее хорошо сохранили химический состав, близкий к протозвездной туманности. На рис. 1 показан количественный состав элементов Солнечной системы, нормированных по отношению углистого хондрита (диаграмма по [Wood, 2011], модифицированная по [Lauretta, 2011]). На графике хорошо видно, что рассматриваемые метеориты имеют состав, сопоставимый с составом Солнца. Исключение представляет Li, который не попадает на линию состава хондрит - Солнце, так как он уничтожается при плавлении в ядре Солнца. В голубом диске (верхняя часть графика) - три элемента (N, C, O), деплетированные в метеоритах, так как они образовали льды в самом начале эволюции Солнечной туманности, которые пошли на образование далеких (Сатурн, Юпитер) планет. В оранжевом диске - элементы, составляющие главную массу ме-

\section{Короткоживущие радионуклиды, присутствовавшие на ранней Земле}

Short-lived radionuclides present in early Earth

\begin{tabular}{llll}
\hline Parent & Daughter & Parent halt-life (megayears) & Extinct alter (megayears) \\
\hline${ }^{182} \mathrm{Hf}$ (lithophile) & ${ }^{182} \mathrm{~W}$ (siderophile) & 8.9 & 45 \\
${ }^{107} \mathrm{Pd}$ (very siderophile) & ${ }^{107} \mathrm{Ag}$ (siderophile) & 6.5 & 35 \\
${ }^{26} \mathrm{Al}$ (lithophile) & ${ }^{26} \mathrm{Mg}$ (lithophile) & 0.7 & 3.5 \\
${ }^{146} \mathrm{Sm}$ (lithophile) & ${ }^{142} \mathrm{Nd}$ (lithophile) & 103 & 500 \\
${ }^{60} \mathrm{Fe}$ (siderophile) & ${ }^{60} \mathrm{Ni}$ (siderophile) & 1.5 & 7.5 \\
${ }^{129} \mathrm{I}$ (lithophile) & ${ }^{129} \mathrm{Xe}$ (atmophile) & 15.7 & 80 \\
\hline
\end{tabular}


M.I. Kuz'min: The Precambrian history of the origin and evolution of the Solar System and Earth...

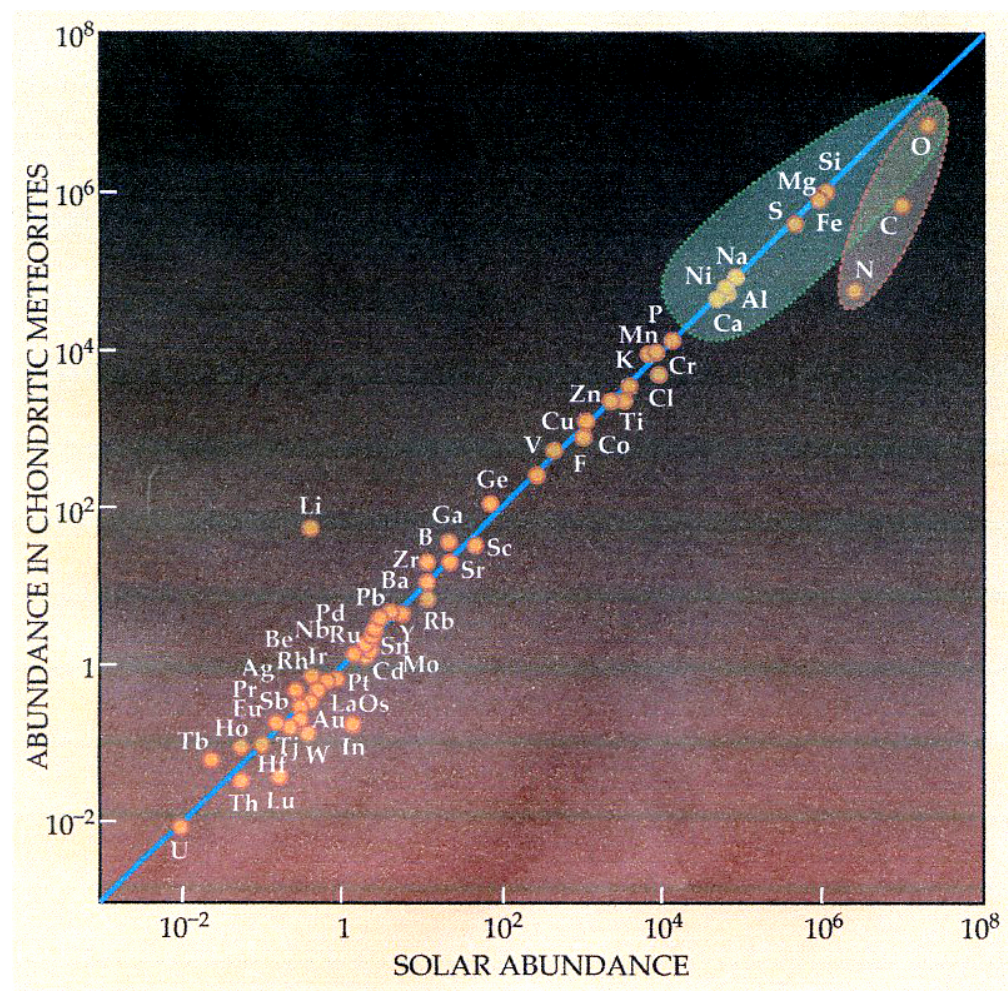

Рис. 1. График количества элементов в поверхности Солнца в сравнении с содержанием элементов в углистом хондрите СI, по [Wood, 2011].

Fig. 1. The curve of the number of elements on the surface of Sun as compared with elements in carbonaceous chondrite, CI according to [Wood, 2011].

теоритов, а также планет земной группы. Как видно на данной диаграмме, 95 \% массы Солнечной системы (кроме Н и Не), а соответственно и планет земной группы составляют Fe, O, Mg, Si и Ni и еще 9 элементов - Cu, Al, S, Cr, Ni, Mn, P, Ti и Со вместе с названными - 99 \% [Lauretta, 2011].

Возвращаясь к началу эволюции Солнечной системы, отметим, что в первые 1.0-1.5 млн лет сформировался лед-материал для наших самых крупных планет Сатурна и Юпитера, которые как планеты образовались за 2 млн лет. Через 2 млн лет после зарождения Солнечной системы сформировались малые тела - метеориты, уже деплетированные компонентами, формирующими ледяные глыбы на дальней оконечности Солнечной системы. После формирования малых тел и планетезималей в планетном диске началось образование планет земной группы. Марс и большие астероиды сформировались около 7 млн лет, 63 \% массы Земли были образованы около 11 млн лет, а 93 \% ее массы через - 30 млн лет после начала формирования Солнечной системы [Wood, 2011].

Земля является высокодифференцированным телом с металлическим ядром и окружающей его твердой силикатной оболочкой. Мы не имеем анализов образцов ядра, но данные по «первичному» составу Земли, определяемые по составу углистых хондритов (ме- теоритов), а также состав силикатной мантии Земли [McDonough, Sun, 1995; Allègre et al., 1995] позволяют оценить состав ядра Земли. Это можно сделать на основании свойств элементов, по отношению их сродства с железом, силикатами и летучестью, т.е. их возможностью, способностью отделиться от твердой Земли, уйти в атмосферу, а в дальнейшем и покинуть солнечную систему, перейдя в космический газ. В этом отношении имеет большое значение знание особенностей отдельных элементов по их сродству с железом, силикатами и летучими. На рис. 2 приведены нормированные содержания элементов в Земле по содержаниям в углистом хондрите, по отношению к температуре конденсации этих элементов, находившихся ранее в Солнечной туманности. При аккреции произошло разделение: тугоплавкие элементы, среди которых выделяются литофильные, имеющие сродство с силикатами, концентрировались в мантии и земной коре; сидерофильные, имеющие сродство с железом и концентрирующиеся в ядре; и летучие, легко переходящие в атмосферу, формировшие газ, который мог легко покинуть Землю. Как видно из рис. 2, тугоплавкие литофильные элементы в силикатной Земле (т.е. в мантии) (BSE) находятся в том же количестве, что и в углистом хондрите. Содержания сидерофильных элементов в мантии понижены по отношению к хондриту - они 


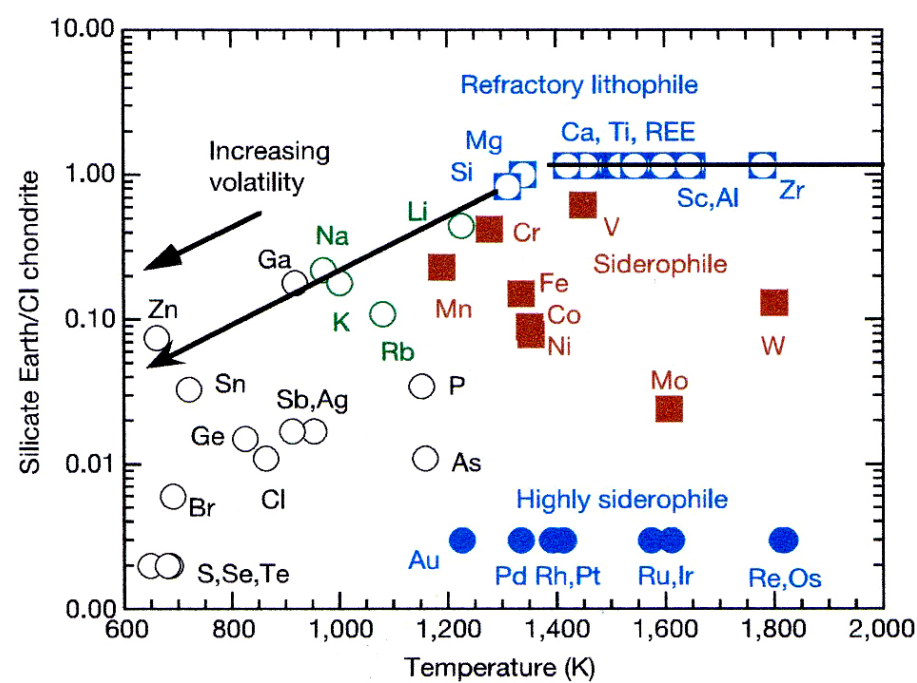

Рис. 2. Количество элементов в силикатной Земле, нормированных по углистому хондриту и по $[\mathrm{Mg}]_{\text {Earth }} /[\mathrm{Mg}]_{\mathrm{CI}}=1.0$ по отношению температуры конденсации элементов Солнечной туманности.

Fig. 2. The number of elements in the silicate Earth, normalized by chondrite and $[\mathrm{Mg}]_{\text {Earth }} /[\mathrm{Mg}]_{\mathrm{CI}}=1.0$ against the condensation temperature of elements of the Solar nebula.

накапливаются в ядре. Самые низкие содержания высокосидерофильных элементов (Pd, Pt, Re, Os и др.) в силикатной Земле. Они максимально концентрировались в ядре. Однако отмечается их некоторое увеличение и в мантии, что, очевидно, связано с «метеоритным дождем», который захватил Землю после формирования большей части ядра [Wood, Halliday, 2010].

Рост Земли и выделение ее ядра происходили при аккреции сначала малых тел, позже при формировании эмбрионов планет, а затем при столкновении с различными метеоритными телами. После формирования Солнечной системы 4568 млн лет назад в ее пределах образовывались мелкие тела, размером до 10 км в диаметре. Они сформировались в течение 10-100 тыс. лет. С одной стороны, столкновение таких мелких тел приводило к их разрушению, с другой - часть из них в результате коллизии сформировали более крупные тела - эмбрионы планет. Во всяком случае, примерно через один млн лет были сформированы тела массой примерно 1 \% от массы Земли. Начала «работать» энергия гравитации, которая способствовала дальнейшему росту этих первых планетных эмбрионов. Существенное значение в судьбе астероидов и планетных эмбрионов имели короткоживущие радионуклиды (таблица), а также такие изотопы, как ${ }^{20} \mathrm{Al}$ (период полураспада - 0.7 млн лет) и ${ }^{60} \mathrm{Fe}$ (период полураспада - 1.5 млн лет). Именно эти изотопы определяли плавление наиболее ранних астероидов и планетезималей.

Для определения возраста выделения ядра используются изотопы ${ }^{182} \mathrm{Hf} \rightarrow$, дающие при распаде ${ }^{182} \mathrm{~W}$.
Наиболее четко это можно проследить на рис. 3, на котором показаны соотношения ${ }^{182} \mathrm{~W} /{ }^{184} \mathrm{~W}$ в ядре, силикатной мантии и углистых хондритах. Большая часть ядра сформировалась около 20 млн лет после образования Солнечной системы. С тех пор в ядре отношение Hf/W стало равно 0, так как Hf - литофильный элемент и он полностью концентрируется в мантии. При этом ${ }^{182} \mathrm{~W} /{ }^{184} \mathrm{~W}$ в углистых хондритах меньше, чем в мантии, потому что «литофильного» гафния больше в мантии, так как он полностью остался в ней и не попал в ядро после I этапа его формирования, при распаде ${ }^{182} \mathrm{Hf}$ оставшийся в мантии обогатил ее ${ }^{182} \mathrm{~W}$ по сравнению с углистым хондритом. Около 50 млн лет, когда весь ${ }^{182} \mathrm{Hf}$ перешел в ${ }^{182} \mathrm{~W}$, отмечается постоянство отношения Hf/W в мантии и в углистых хондритах. Это время окончательного формирования ядра.

Формирование ядра было возможным при существовании глубокого (400-600 км) магматического океана (рис. 4), так как при высокой температуре и давлениях 20-23 gПа устанавливается равновесие между расплавом силикатов и железом. При бомбардировке крупными астероидами с учетом разогрева аккретированного вещества могут формироваться крупные магматические бассейны глубиной до 400 км, в которых происходит разделение железа и силикатов. При крупном импакте, при котором была сформирована Луна, скорее всего, был образован магматический океан по всей поверхно-

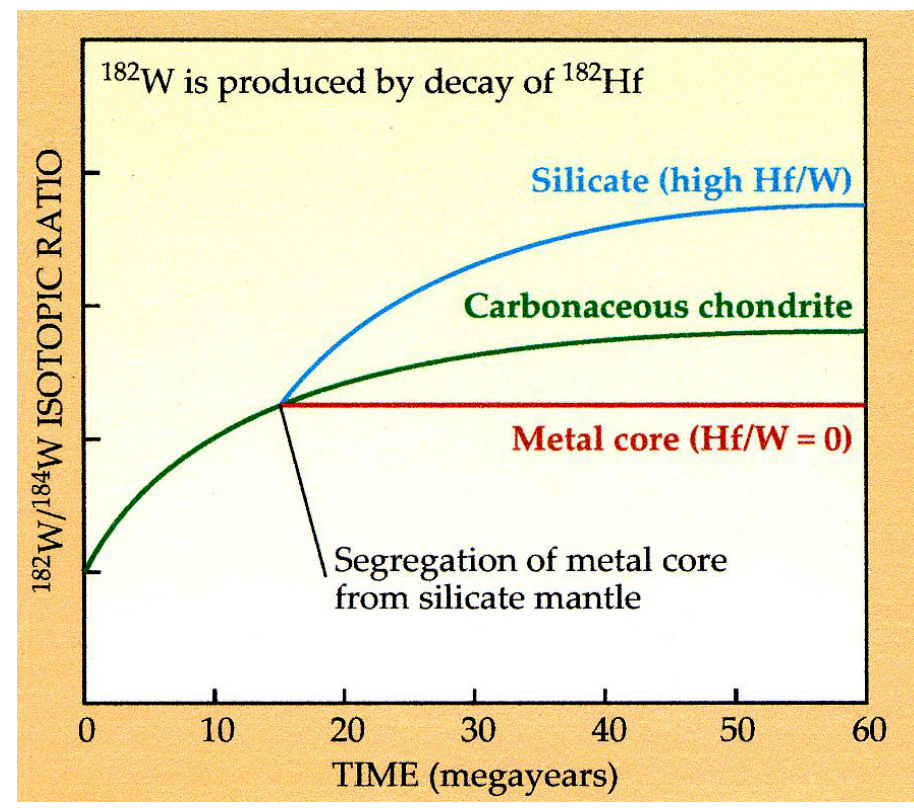

Рис. 3. Отношение двух стабильных изотопов вольфрама, определенных в различных системах (металлическое ядро, углистые хондриты, силикатная мантия) по [Wood, 2011].

Fig. 3. The ratio of two stable isotopes of tungsten in different systems (metal core, carbonaceous chondrite, and silicate mantle) according to [Wood, 2011]. 


\section{Accreting body \\ Molten silicate}

Iron droplets

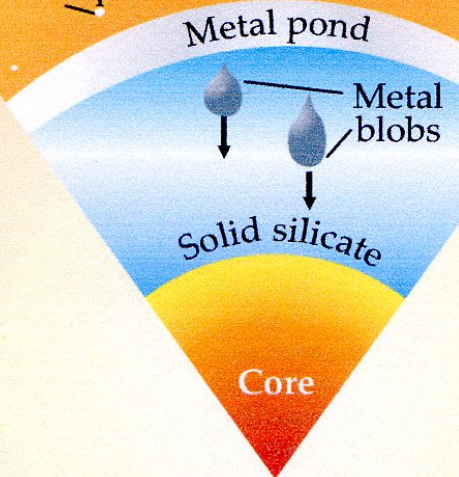

Рис. 4. Модель образования ядра с «использованием» глубокого магматического океана по [Wood, 2011; Wood et al., 2006].

Fig. 4. The model showing the formation of the core with the 'use' of the deep magma ocean according to [Wood, 2011; Wood et al., 2006].

сти Земли, глубина его достигала 700 км. На рис. 4 видно, что астероиды, достигавшие Земли, поставляли в магматический океан капли железа (сидерофильных элементов), которые опускались до дна океана, где находился расплавленный металлический резервуар, названный металлическим прудом [Wood, 2011], который был нестабилен по отношению к силикатной мантии. В этом резервуаре образовались крупные шарообразные тела, равновесные с расположенным ниже твердым силикатным веществом, которые опускались и наращивали ядро. Предполагается, что его формирование происходило в течение 50 млн лет после начала формирования Солнечной системы (см. рис. 2). Правда, если использовать для отсчета времени другие изотопы системы, а не ${ }^{182} \mathrm{Hf} \rightarrow{ }^{182} \mathrm{~W}$ [Wood, 2011], то, возможно, это происходило более долго.

Ядро состоит из $85 \% \mathrm{Fe}$ и $5 \% \mathrm{Ni}$, относительно высоки содержания Cr ( 0.9 \%) и Со ( 0.25 \%) [Wood et al., 2006]. Кроме того, в ядре находится около $8 \%$ легких элементов: $\mathrm{H}, \mathrm{O}, \mathrm{C}, \mathrm{S}, \mathrm{P}$ и $\mathrm{Si}$; возможно, есть сульфиды, главным образом ZnS. Концентрация серы достигает 1.9 \%, а кремнезема - 6-7 \% [Allègre et al., 1995]. Наличие легких элементов в ядре имеет важное значение для формирования плюмов, особенно в фанерозое, когда уже сформировался на границе ядро мантия слой $\mathrm{D}^{\prime \prime}$, что будет детально рассмотрено во второй статье.

Важным событием в Хаотичный эон было образование Луны - единственного спутника Земли. Как счи- тает большинство исследователей, столкновение случилось в конце процесса аккреции Земли, во всяком случае, когда она уже имела массу около 60-70 \% по сравнению с современной. Крупное тело, масса которого была близка к массе Марса, столкнулось с Землей, которая к этому времени (30-40 млн лет после формирования Солнечной системы) уже в значительной степени была дифференцирована, а большая часть ядра сформирована. При ударе большое количество силикатного вещества от Земли и импакта было выброшено в район орбиты Луны, которая в то время находилась в пределах трех земных радиусов [Binder, 1982; Zharkov, 2000]. Обломки силикатных пород мантии Земли и импакта послужили основой для формирования тела Луны. Лунные породы характеризуются обедненностью сидерофильными элементами, которые во время столкновения с Землейв большом количестве были сконцентрированы в ядре. Следовательно, удар не расколол Землю, а только произошел большой выброс в космическое пространство материала силикатной мантии Земли. Но если в Земле сидерофильные элементы сосредоточены в ядре, которое составляет 32 \% массы Земли, то Луна имеет очень небольшое ядро [Wood, 2011]. Отсутствие изотопа ${ }^{182} \mathrm{~W}$ в первую очередь указывает на отсутствие сидерофильных элементов на Луне, а с другой стороны - отмечает большое сходство лунных пород с силикатной Землей по многим компонентам и изотопам, хотя по расчетам предполагается, что 80 \% обломков, собранных Луной, - это обломки импакта. Очевидно, для окончательного вывода об источниках вещества Луны необходимо дальнейшее изучение природы импакта, а также особенностей его столкновения с Землей [Wood, 2011].

В настоящее время мы еще мало знаем о геохронологии этого первого этапа развития Земли. Уже сейчас применение разных изотопных систем может дать различный возраст окончательной аккреции Земли - от 45 до 100 млн лет [Wood, 2011; Wood et al., 2006]. Во всяком случае считается, что Гаденский эон, гаденский этап докембрийской истории Земли начинаются 4.5 млрд лет тому назад [Goldblatt et al., 2010].

\section{2. ГАДЕНСКИЙ ЭОН}

Как отмечают авторы [Goldblatt et al., 2010], Гаденский эон ограничен, вернее выделяется по началу земной геологии, в отличие от процессов Хаоса, свойственных ранней истории эволюции Солнечной системы. Второе, на что обращают внимание эти авторы, Гаденский эон начинается после формирования системы Земля - Луна. Это действительно так, поскольку одновозрастные цирконы обнаружены на этих двух объектах Солнечной системы (см. ниже). Выделение Гаденского эона геологическим научным сообществом началось в какой-то мере неожиданно в связи с находками цирконов возраста 4.376 млрд лет в Австралии в осадочных разрезах Jack Hills, обнаруженных на тер- 


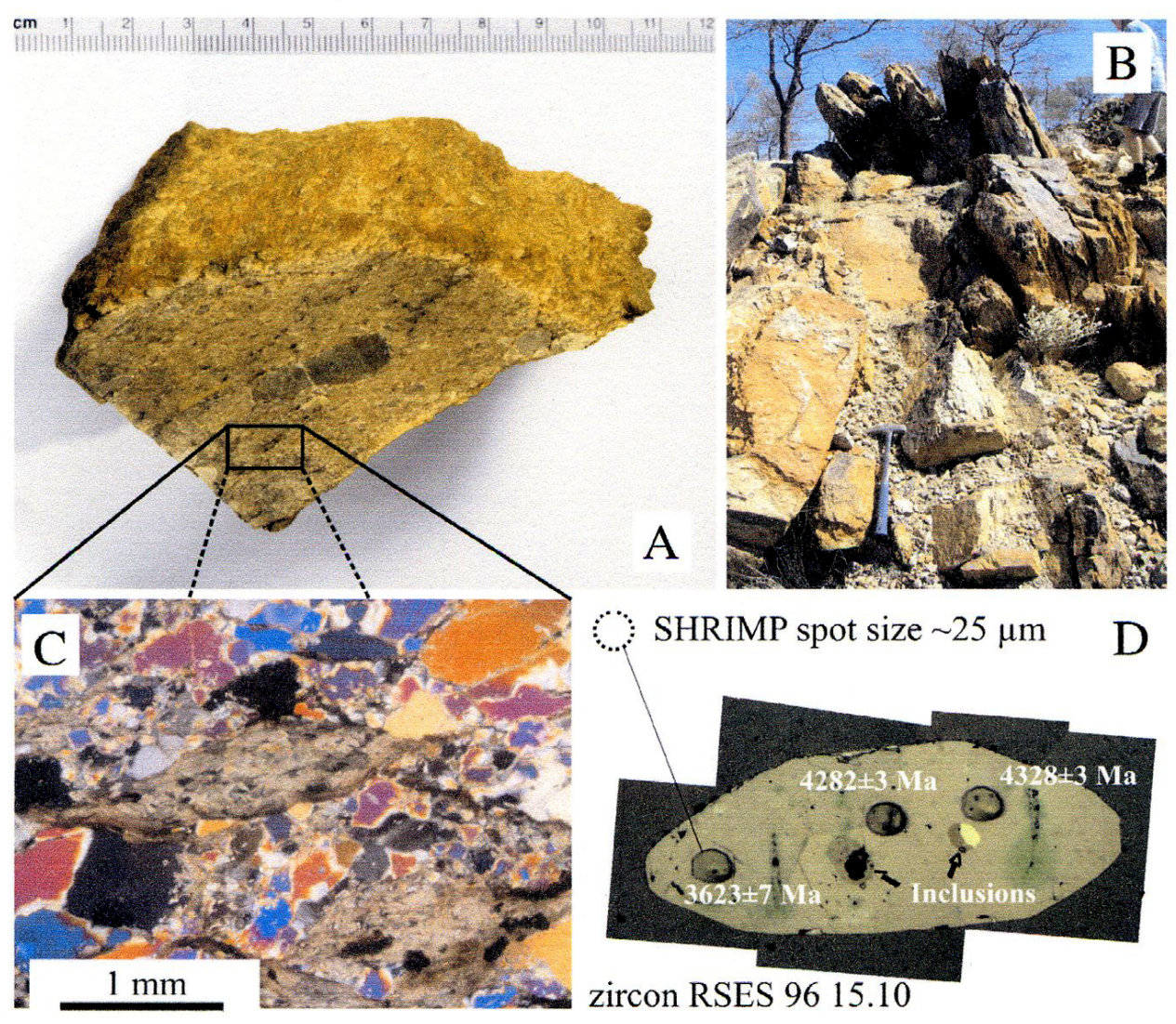

Рис. 5. По [Nebel et al., 2014]: A - образец из обнажения Jack Hills с большой кварцевой галькой в центре. Видны большие вариации в размерах зерен; B - образец с обнажения W74 [Compston, Pidgeon, 1986] в районе Jack Hills? Западная Австралия, где гаденские зерна были впервые открыты; $C$ - шлиф с вытянутой галькой кварца среди других мелких кластических зерен (кварц, слюда) с деформированными структурами; D - снимок кристалла циркона RSES 96 15.10, показывающий три различных возраста в едином зерне, определенных методом SHRIMP в Австралийском национальном университете. Кристалл содержит включения, которые изучаются.

Fig. 5. From [Nebel et al., 2014]: A - a sample from a rock outcrop in the Jack Hills region, West Australia with quarts pebbles in the centre shows significant variations of grain sizes; $B$ - a sample from W74 outcrop [Compston, Pidgeon, 1986] near Jack Hills where grains of the Hadean eon were first found; $C$ - a thin section containing elongated quartz pebbles among other minor clastic grains (quartz, mica) with deformed structures; $D$ - an electron microscope image of a zircon crystal (RSES 96 15.10) showing three different age groups in a single grain as defined by SHRIMP at the Australian National University. The crystal contains inclusions under study.

рейне Narrger кратона Yilgarn (Илгарн) (Западная Австралия). Narrger террейн присоединился к Илгарн кратону, судя по стратиграфическим данным, 2.7-2.6 млрд лет тому назад [Myers, 1988]. Само «месторождение» древних цирконов Jack Hills имеет площадь выхода около $4 \times 4$ м (рис. 5), а представлено оно метаморфизованными обломочными осадками, среди которых отмечают обломки разной размерности, от крупных обломков кварца до его мелкозернистой массы, что говорит об их происхождении в мелководной обстановке при слабой сортировке. В осадках находится большое количество обломков цирконов. Древние гаденские возрасты отмечаются только в центральных частях зерен циркона, а периферийные зоны представлены более молодыми цирконами, минимальный возраст которых составляет всего 3.0 млрд лет. Очевидно, тогда завершилось формирование данной осадочной свиты (рис. 5). Еще раз подчеркнем, что гаденские возрасты зафиксированы только в центральных частях зерен цирконов. Все это говорит о том, что до времени отложения обломков цирконов в осадки Jack Hills цирконы после кристаллизации в ранних гаденских магмах находились в первых континентальных породах, которые попадали в мантию, где в цирконах при рециклинге вырастали дополнительные более молодые зоны. W. Compston, R. Pidgeon [Compston, Pidgeon, 1986] проанализировали из обнажения Jack Hills 140 обломков - количество анализов более 100000 , результаты анализов показаны на (рис. 6). Древние возрасты были установлены только в центральных частях обломков и только в 17 случаях. Их возраст был в диапазоне от $>4.0$ до 4.276 млрд лет. Самый древний возраст 


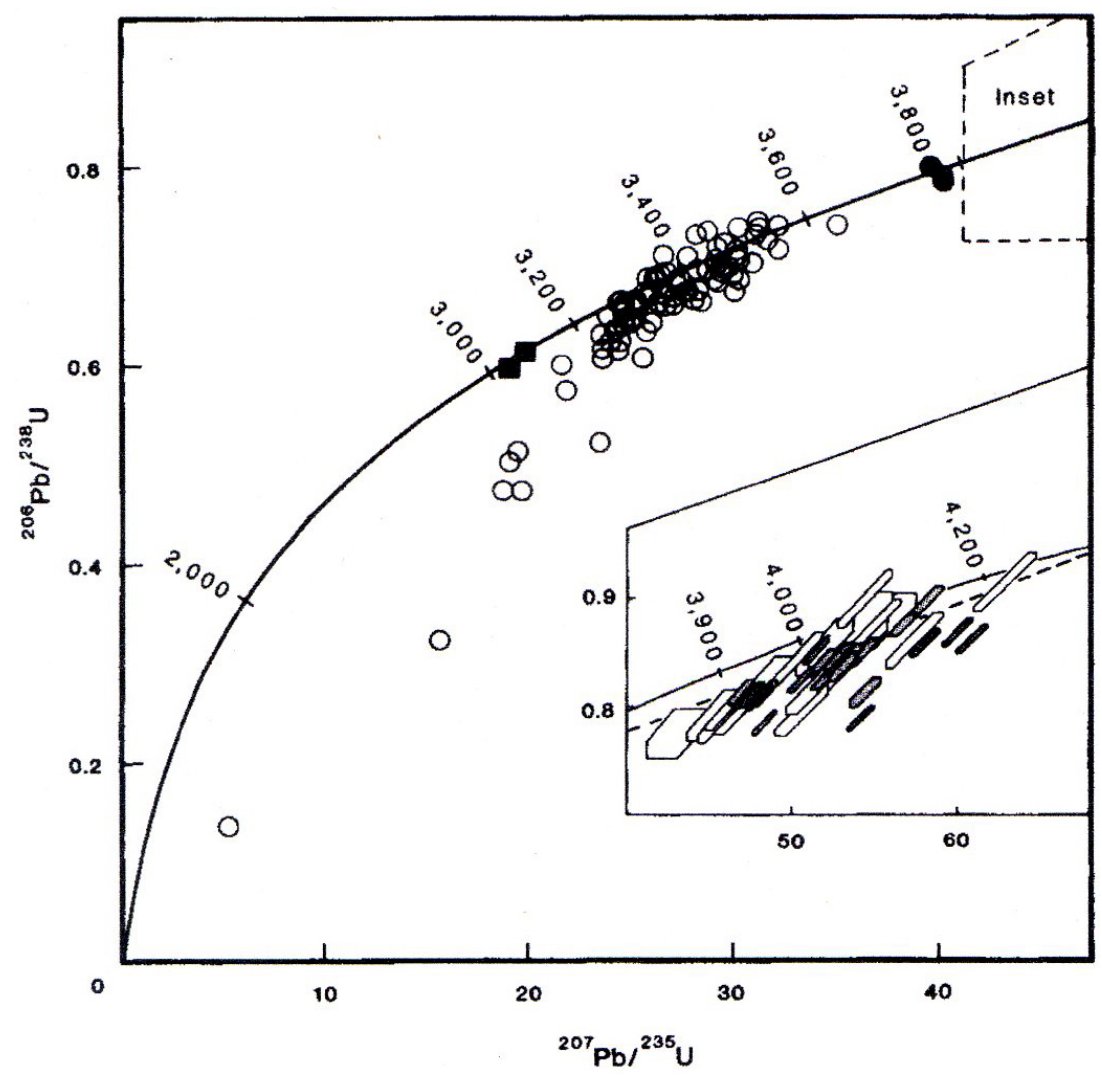

Рис. 6. Диаграмма конкордия U-Pb возраста 140 обломков из конгломератов Jack Hills по [Compston, Pidgeon, 1986].

На главной диаграмме показаны все анализы обломков цирконов из осадков Jack Hills. На врезке показаны данные по 17 анализам с возрастом более 4.0 млрд лет.

Fig. 6. Concordia U-Pb age diagram for 140 rock pieces from conglomerates sampled from the rock outcrop in the Jack Hills region [Compston, Pidgeon, 1986].

The main diagram represents all the analyses of zircon chips from the Jack Hills sediments. The insert shows data from 17 analyses of samples which ages are over $4.0 \mathrm{Ga}$.

(4.376 млрд лет) установлен ранее. Почти все крупные ученые признавали этот интересный факт, но учесть его не могли. Однако после открытия гаденских цирконов на обнажении Jack Hills (особенно в XXI в.) начали проводить большое количество исследований с применением многочисленных аналитических методов, с использованием современных прецизионных аналитических приборов, настало время понимания условий формирования Гаденской коры, а также ее судьбы в докембрии.

Были проанализированы образцы с возрастом более 3800 млн лет (рис. 7). Гистограмма полученных возрастов приведена в работе [Holden et al., 2009]. Количество цирконов с возрастом более 3.8 млрд лет составляет $7.3 \%$ [Holden et al., 2009], для этой серии возрастов пик отвечает возрасту 4.0-4.1 млрд лет (рис. 7). Основная масса цирконов в осадки попадает, очевидно, при разрушении древних пород Илгарнского кратона. При этом практически все цирконы зональны. На основной гистограмме (рис. 7) приведена врезка, на которой более четко просматривается часть возрастов цирконов более 4100 млн лет. На гистограмме видно, что небольшой пик максимальных возрастов цирконов отвечает 4.1 млрд лет. Очевидно, он фиксирует завершение Гаденского эона. Цирконы с более молодым возрастом поступали уже при разрушении докембрийских пород Илгарнского кратона. На кратоне широко развиты древние архейские породы, представленные как основными (мафическими) гнейсовыми комплексами, так и гнейсовыми кислыми комплексами, так называемыми серыми гнейсами, сложенными трондьемит-гранодиорит-гранитной ассоциацией пород, широко представленными на Австралийском Илгарнском кратоне [Kinny et al., 1990], так же как и на других древних кратонах [Khain, 2003]. Самое главное, что в них широко представлены цирконы, имеющие много родственного с гаденскими цирконами [Nebel et al., 2014], что мы подробнее рассмотрим ниже.

Несомненно, важное значение имеют данные по продолжительности Гаденского эона. Вполне понятно, что такую информацию можно получить при анализе 


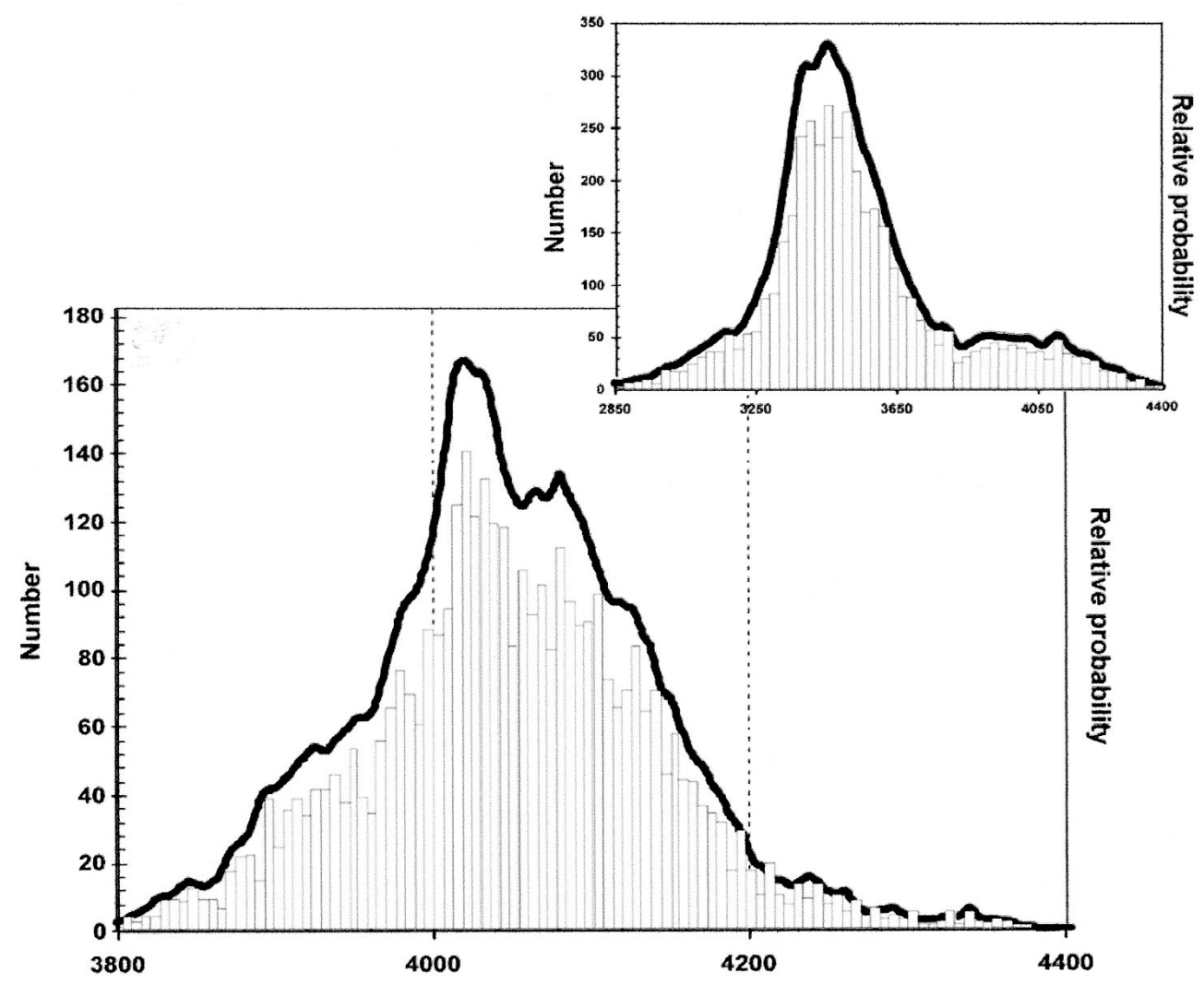

Рис. 7. Гистограмма возрастов обломков цирконов из обнажения Jack Hills [Holden et al., 2009].

Пик возрастов в интервале 4.00-4.05 млрд лет. На вставке диаграммы приведен больший масштаб для интервала 4.05-4.40 млрд лет.

Fig. 7. Histogram of ages of zircon chips from Jack Hills outcrop [Holden et al., 2009].

Peak ages range from 4.00 to $4.05 \mathrm{Ga}$. The insert shows data for the interval from 4.05 to $4.40 \mathrm{Ga}$.

единого зерна, имеющего много зон, образованных в разное время. Если тектоническая активность, вызывавшая рециклинг коровых цирконов, была быстрой, то зерна с возрастом от 4.34 млрд лет до окончательного времени формирования пород (скорее всего, серых гнейсов) должны зафиксировать такие события. Такое исследование с образцом RSES96-15.10 с возрастом в центре 4.34 млрд лет было проведено авторами работы [Holden et al., 2009]. Сделаны порядка 100000 определений возрастов и 50 \% перекрывающих анализов. Автоматические анализы сделаны на базе SHRIMPI и SHRIMP-Pg. Результаты этого исследования представлены на рис. 8 [Holden et al., 2009], на котором видно, что зерно имеет самый древний возраст 4.35 млрд лет, а наибольшее количество определений дает 4.25 млрд лет. На гистограмме хорошо видны семь событий, запечатленных в гаденском цирконе. Большой пик на гистограмме характеризует основной возраст формирования гаденских цирконов - 4.25 млрд лет, а следовательно, и Гаденской коры. Другие значения возраста зерна циркона с пиком 4.1 млрд лет и менее соответствуют более молодым событиям переработки гаденских цирконов в архейское время. Очевидно, что воз- раст 4.1 млрд лет представляет собой, скорее всего, окончание Гаденского эона [Nebel et al., 2014], тем более что этот же возраст определяется при исследовании закономерности распределения изотопов гафния в Jack Hills [Blichert-Toft, Albarède, 2008].

Таким образом, продолжительность Гаденского эона составляет 4.1-4.5 млрд лет с максимальным возрастом роста континентальной коры в 4.25 млрд лет. В последнее время вблизи обнажения Jack Hills древние цирконы были найдены в районе Mt. Narryer, а также на востоке Илгарнского кратона, однако детальные исследования этих месторождений древних цирконов еще не проводились. Возможно, они дадут новые сведения о гаденской истории нашей планеты.

Геохимия редких элементов в цирконах может дать много сведений о природе и генезисе магм, родительских для цирконов. Первые результаты по содержанию редких элементов в гаденских цирконах были получены Р. Маасом и коллегами [Maas et al., 1992]. Они показали, что исследуемые цирконы имеют содержания Hf - 0.86-1.30 вес. \%; Zn/Hf - 30-57; фракционирование РЗЭ (высокое отношение ТРЗЭ/ЛРЗЭ) характеризуется положительной Се и отрицательной 


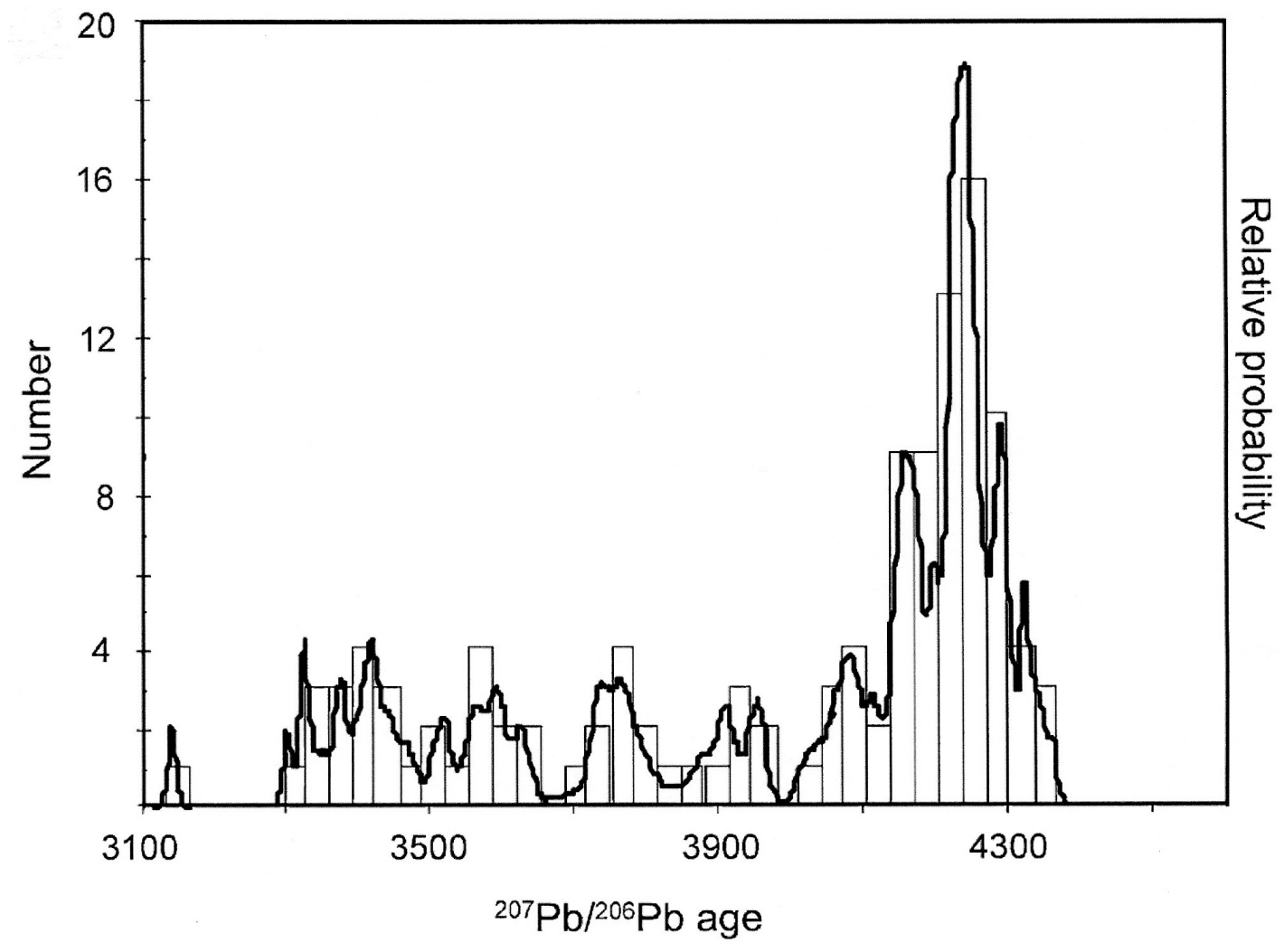

Рис. 8. Гистограмма локальных возрастов ${ }^{207} \mathrm{~Pb} /{ }^{206} \mathrm{~Pb}$ в образце RSES96-15.10 из обломков цирконов обнажения Јасk Hills, оцененных автоматическим анализом определения изотопов свинца на базе SHRIMPI и SHRIMP-Pg [Holden et al., 2009].

Fig. 8. Histogram of local ages of ${ }^{207} \mathrm{~Pb} /{ }^{206} \mathrm{~Pb}$ in Sample RSES96-15.10 of zircon chips from the rock outcrop in the Jack Hills region; data are obtained by automated lead isotope analyses on the basis of SHRIMPI and SHRIMP-Pg [Holden et al., 2009].

Eu аномалиями. Эти же исследователи показали присутствие в цирконах включений: калиевого полевого шпата, кварца, плагиоклаза, моноцита и апатита. Все это позволило авторам сделать заключение о гранитном составе источника гаденских цирконов. Позднее были открыты микроалмазные включения в цирконах Jack Hills [Menneken et al., 2007]. Кроме того, важным было открытие цирконов близкого возраста на Луне.

Очевидно, сравнение цирконов Луны и земных гаденских цирконов представляет интерес. На рис. 9 показаны данные о возрасте и температуре образования лунных цирконов [Taylor et al., 2009]. U-Pb возраст был определен для 39 цирконов, анализ проводили в отдельных точках с помощью Camera ins P70 ion microprobe UCLA и SHRIMP в Австралийском национальном университете, т.е. там же, где выполнялись основные анализы возраста гаденских обломков цирконов из обнажений Jack Hills. Как видно на гистограмме (рис. 9, А), возраст находится в диапазоне 4.00-4.35 млрд лет, т.е. цирконы одновозрастные с земными гаденскими. В то же время температура кристаллизации лунных цирконов по Ті-цирконовому термометру значительно выше гаденских (рис. 9, Б). Температура кристаллизации лунных цирконов 920-
$1140{ }^{\circ} \mathrm{C}$, в то время как гаденских $-700{ }^{\circ} \mathrm{C}$ в среднем [Harrison et al., 2008]. Отличаются лунные цирконы от гаденских отсутствием Се-положительной аномалии (рис. 10). Наличие цериевой положительной аномалии указывает на то, что окислительные условия были на Земле при формировании Гаденской континентальной коры, так как Се, который может иметь валентность $\mathrm{Ce}^{4+}$, в случае окислительных условий легко входит в цирконы. Лунные цирконы кристаллизованы в восстановительной среде.

Большое значение для восстановления условий кристаллизации цирконов в гаденское время имеют изотопы кислорода. Необходимо указать, что изотопы кислорода изверженных пород фракционируют во время магматической дифференциации. Эти соотношения могут быть существенно изменены в процессах выветривания. При выветривании легкий изотоп предпочтительнее выщелачивается из пород, поэтому оставшиеся после выветривания породы имеют высокое значение $\delta^{18} \mathrm{O}$ по сравнению с первичными породами. На основании изучения состава изотопов кислорода можно сделать два основных вывода о характере окружающей среды в Гадее [Nebel et al., 2014]: 1) гаденские процессы выветривания подобны современным, 

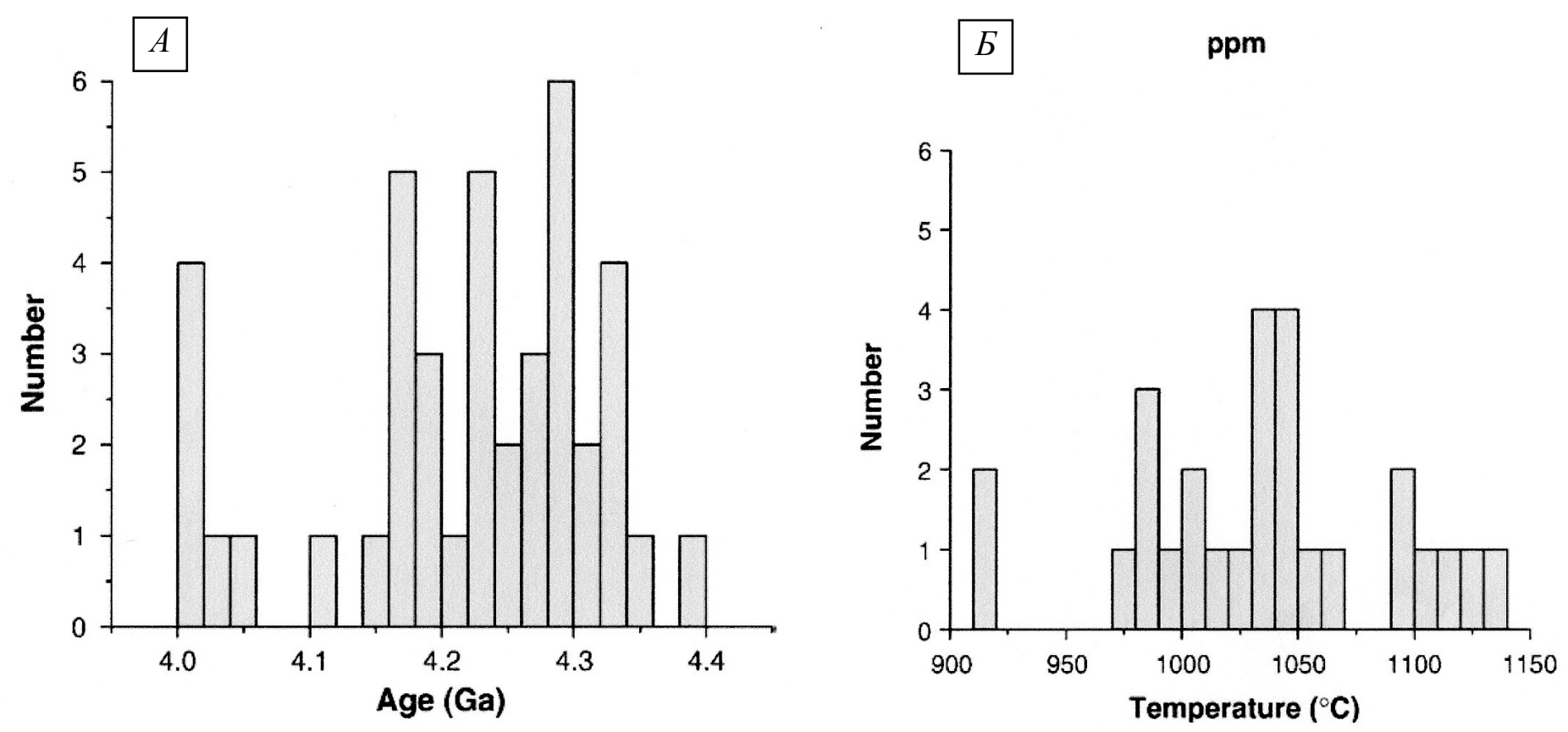

Рис. 9. A - гистограмма ${ }^{207} \mathrm{~Pb} /{ }^{206} \mathrm{~Pb}$ в лунных цирконах по [Taylor et al., 2009]; Б - гистограмма температуры кристаллизации лунных цирконов по [Taylor et al., 2009].

Fig. 9. $A$ - histogram of ${ }^{207} \mathrm{~Pb} /{ }^{206} \mathrm{~Pb}$ in lunar zircons [Taylor et al., 2009]; $Б$ - histogram of lunar zircon crystallization temperature estimations [Taylor et al., 2009].

что дает основание полагать, что ранняя атмосфера Земли была влажной; 2) образование цирконов указывает на то, что парциальное плавление мантийных пород, давших магмы для Гаденской коры, происходило в близповерхностных условиях.

Важный вывод по лунным кристаллам цирконов был сделан при изучении микроструктуры цирконов [Grange et al., 2013]. В них встречены локальные участки перекристаллизации, локализованные аморфные участки, кристаллопластические деформации и разрывы, трещины, т.е. типичные следы импактных структур. В гаденских цирконах из обнажения Jack Hills были найдены включения алмазов [Menneken et al., 2007]. Как представляется, такая находка может указывать на роль импактов при образовании гаденской коры. Однако спектр кондиционного рассеяния (так называемый Roman спектр) показал, что гаденские алмазы не имеют сходства с теми, которые образованы при паде-
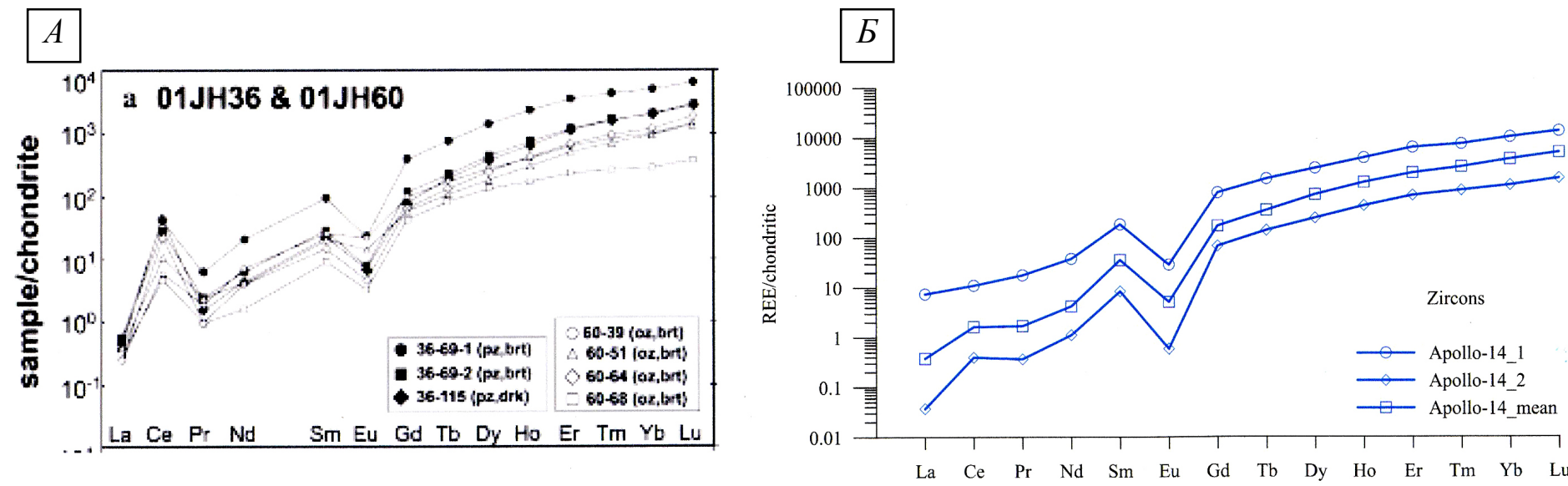

Рис. 10. Нормированные распределения РЗЭ: А - в гаденских цирконах по [Maas et al., 1992]; Б - в лунных цирконах [Тауlor et al., 2009].

Fig. 10. Normalized distribution of rare-earth elements in Hadean zircons [Maas et al., 1992] (A) and lunar zircons [Taylor et al., 2009] (Б). 


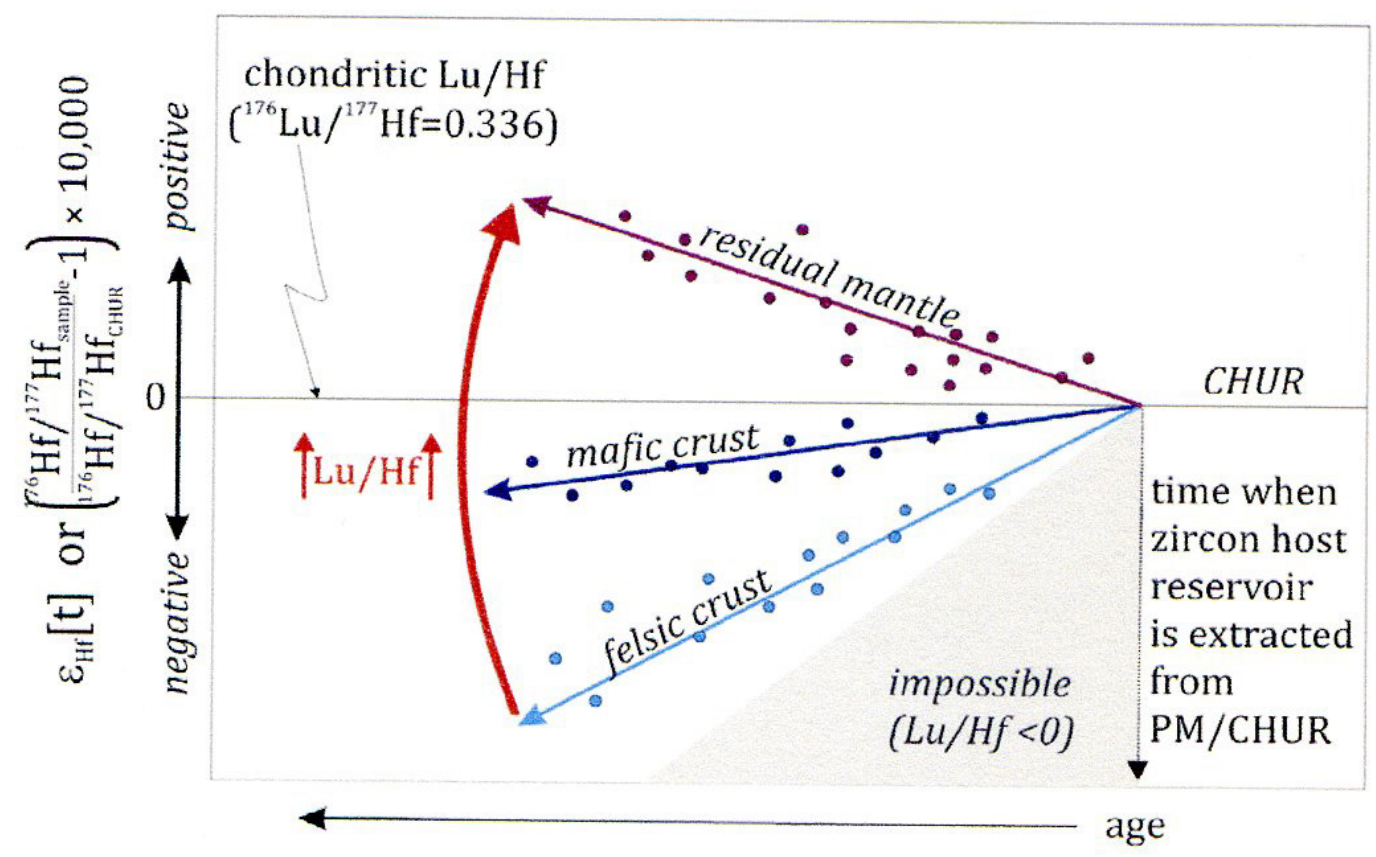

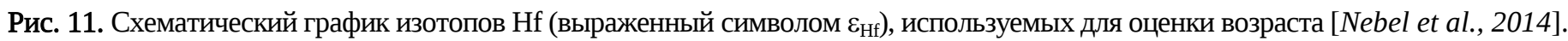

Отдельные точки иллюстрируют анализы цирконов из единой коровой области. Медиана через такую «популяцию» может использоваться для того, чтобы получить Lu/Hf, требуемое для эволюции изотопа, связанного с наклоном медианы. Lu/Hf может, в свою очередь, использоваться, чтобы оценить геохимическую природу коровой области. Высокие величины указывают на мафическую кору, тогда как низкие величины являются представительными для фельзитовой коры. Эти особенности определяются из относительного разделения Lu и Hf во время частичного плавления.

Fig. 11. Isotope Hf / age curve [Nebel et al., 2014].

Points refer to analyses of zircons from the same core area. A median across the «population»of analyzed zircons can be used to obtain a Lu/Hf ratio required for the evolution of the isotope related to the median's angle. In its turn, the $\mathrm{Lu} / \mathrm{Hf}$ ratio can be used to assess the geochemical origin of the core area. High values are indicative of the mafic core, while low values represent the felsitic core. These specific features are determined from a relative division of $\mathrm{Lu}$ and $\mathrm{Hf}$ in the course of partial melting.

нии метеоритов, т.е. с импактом. Цирконы из кимберлитов, т.е. образованные при больших давлениях, также имеют большие отличия от гаденских алмазов. K сожалению, происхождение включений микроалмазов в цирконах Jack Hills в настоящее время не ясно. Отметим только, что лунные и земные гаденские цирконы имеют существенные различия, хотя время появления на Земле и на Луне практически одинаково. Очевидно, эти два крупных тела подвергались во время формирования древних цирконов метеоритной бомбардировке.

Очень важны исследования изотопов Lu-Hf в качестве геохимических трассеров, которые могут помочь в решении проблемы происхождения гаденских цирконов. Лютеций при распаде переходит в гафний $\left({ }^{176} \mathrm{Lu} \rightarrow{ }^{177} \mathrm{Hf}\right)$, период полураспада которого составляет $35.7 \pm 1.2$ млрд лет. Гафний изоморфно связан с цирконом. Цирконы могут содержать до нескольких десятков тысяч ppm гафния. Во время формирования цирконов изотопная система гафния «замораживается» в этом минерале, поэтому требуется небольшая корреляция возраста, чтобы получать важную геохимическую информацию о природе первичных пород [Nebel et al., 2014]. Следует отметить, что исследование изо- топов в цирконах стало методом в изучениях цирконов как в Jack Hills, так и в других более поздних магматических объектах. Это положение можно пояснить с помощью рисунка (рис. 11). При интерпретации количества радиогенного ${ }^{177} \mathrm{Hf}$ весьма значима $\varepsilon_{\mathrm{Hf}}[\mathrm{t}]$, величина которого связана с содержанием изотопов гафния в хондритах. Этот параметр представлен на рис. 11. Следует пояснить, что $\varepsilon_{\mathrm{Hf}}[\mathrm{t}]$ показывает отклонение ${ }^{176} \mathrm{Hf} /{ }^{177} \mathrm{Hf}$ от хондритового однородного недифференцированного резервуара (т.е. от хондритового резервуapa), отвечающего примитивной мантии, за время $t$. Важно, чтобы определение изотопов Hf проводилось локальным методом; в противном случае при зональных цирконах мы будем иметь суммарное значение соотношения изотопов гафния, которые невозможно отнести к какому-то точному времени. Необходимо также отметить, что ${ }^{176} \mathrm{Hf} /{ }^{177} \mathrm{Hf}$ для основной мафической коры близко к 0.03 , а кислой фельзитовой $<0.012$ [Nebel et al., 2014].

Мы отмечали, что обломки цирконов из обнажения Jack Hills практически все зональны, а при определении возраста из единого кристалла (см. рис. 8) хорошо видно, что постепенно происходит рециклинг, 


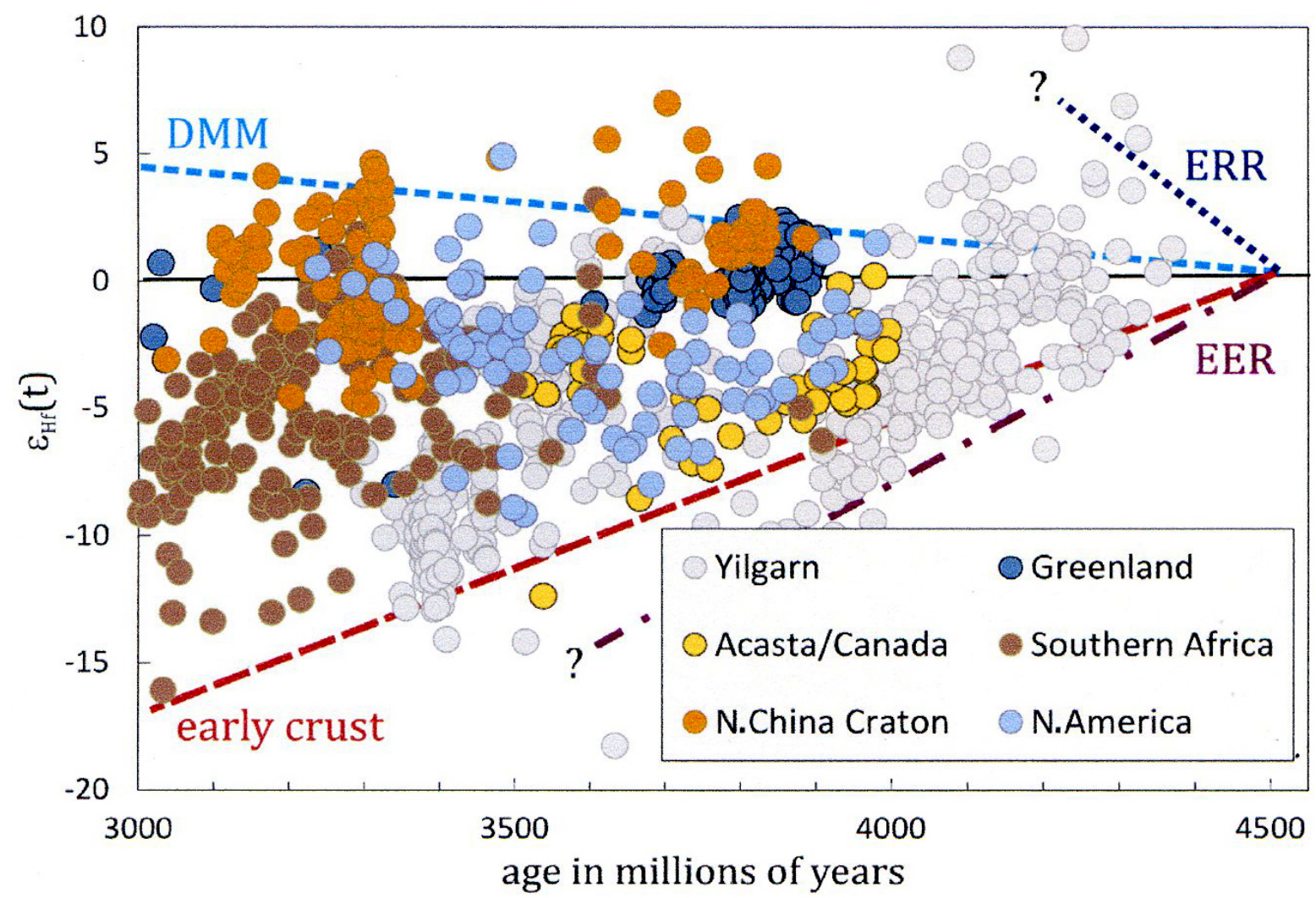

Рис. 12. Глобальная компиляция (сравнение) обломков цирконов, обнаруженных в осадках, сформированных при разрушении серых гнейсов кратонов Австралии, Канады, Северного Китая, Гренландии, Южной Африки и Северной Америки, показана на модернизированной диаграмме [O’Neil et al., 2010].

Диаграмма рис. 12 дана по [Nebel et al., 2014]. ERR - ранний остаточный резервуар; EER - ранний обогащенный резервуар; DMM - деплетированная мантия (пояснения см. в тексте).

Fig. 12. A diagram showing global comparison of zircon chips found in sediments resulting from crushing of grey gneisses in cratons in Australia, Canada, North China, Greenland, South Africa and North America (modified [O'Neil et al., 2010]).

The diagram in Figure 12 is given according to [Nebel et al., 2014]. ERR - Early Refractory Reservoir; EER - Early Enriched Reservoir; DMM depleted mid-oceanic mantle. See explanations in the text.

т.е. гаденские цирконы служат основой (родительским радионуклидам) для формирования цирконов более поздних, в основном серых, гнейсов, являющихся основой Западно-Австралийского кратона Илгарн. Если говорить о всем поколении цирконов в осадках обнажения Jack Hills, то его можно назвать популяцией цирконов Илгарн. Ясно, что если рассматривать эту «популяцию» по отношению $\varepsilon_{\mathrm{Hf}}[\mathrm{t}]-$ возраст (рис. 12), то она должна быть широко представлена на графике, занимая пространство с различными значениями $\varepsilon_{\mathrm{Hf}}[\mathrm{t}]$ - от положительных до отрицательных. При этом данные по изотопам ${ }^{176} \mathrm{Hf} /{ }^{177} \mathrm{Hf}$ показывают, что все возрасты Илгарнской популяции базируются на гаденских цирконах возраста 4.2-4.3 млрд лет. В связи с этим интересно было определить положение цирконов на диаграмме $\varepsilon_{\mathrm{Hf}}[\mathrm{t}]-\mathrm{T}$ (возраст). K настоящему времени уже получены данные, что цирконы, имеющие широкий диапазон значений возраста, отмечаются в пределах различных кратонов, а именно - в канадских гней- cax Акаста, песках реки Миссисипи, где они получены при разрушении Южно-Африканского кратона, в кратонных породах Гренландии, в архейских осадках Северного Китая [Nebel et al., 2014]. Все эти обломочные цирконы (так как в основном они обнаружены в архейских осадочных разрезах) формировались и перерабатывались из единого источника - гаденских цирконов. Отсюда делаются важные выводы: во-первых, гаденская кора была широко распространена, охватывая большие районы нашей Земли; во-вторых, возможно, древние кратоны, известные в настоящее время на разных континентах, ранее были вместе и представляли единый континент [Glukhovsky et al., 1994, Glukhovskii, Kuz'min, 2013], который подвергался тяжелой метеоритной бомбардировке, определившей разрушение первой гаденской коры и погружение ее в глубину мантии. В дальнейшем в результате архейских геологических событий она могла служить прародителем цирконов, а возможно и самих пород трондьемит - 
гранодиорит - гранитной ассоциации, являющихся основой древних архейских образований - серых гнейсов. Таким образом, находки подобных древних цирконов, со следами переработки первой континентальной коры Земли - гаденской коры, являются свидетельством разнообразной ранней архейской тектонической обстановки, природу которой еще необходимо понять. К сожалению, таких образований, т.е. древних цирконов, мы еще не обнаруживали на Северо-Азиатском континенте. (Очевидно, российским геологам следует начать участвовать в таких исследованиях. Для этого необходимо обеспечить наши исследования современным аналитическим оборудованием, позволяющим проводить локальные геохимические исследования с высокой точностью).

\section{3. ЗАКЛЮЧЕНИЕ}

Необходимо суммировать имеющиеся знания по древнейшей гаденской истории нашей планеты. Они хорошо коррелируют с выводами [Nebel et al., 2014].

Геологический мир заинтересован в оценке времени формирования первой континентальной коры на Земле. Она непрерывно росла от зарегистрированного пика ее формирования возрастом 4.25 млрд лет до времени 4.1 млрд лет лет назад - завершения Гаденского эона. Возможно, это (4.1 млрд лет) поворотная точка в ранней геологической истории Земли, после которой началась ее более поздняя архейская история. Почти все гаденские цирконы имеют зональное строение, что дает основание предполагать различные геологические события в ранней (гаденско-архейской) истории нашей планеты. K сожалению, мы пока не знаем первичных гаденских протолитов, однако будущие работы могут помочь нам их найти. Обнадеживающими в этом отношении являются исследования [O'Neil et al., 2013] по древним породам, расположенным вдоль северо-восточного побережья Гудзонова пролива (Канада), которые используют для определения возраста серии изотопов, в том числе накопленных в породах короткоживущих изотопов, и расчет окончательного возраста по долгоживущим изотопам с учетом следов короткоживущих. Многие сомневаются в корректности данных построений. В этом отношении Карл Циммер (2014), который описал сложности данного спора в статье «Древнейшие породы Земли» («В мире науки», № 5, 2014), правильно заметил, что «разрешение споров зависит от усовершенствования методов определения геологического возраста по атомам мельчайших образцов горных пород зарождающейся Земли».

На основе редкоэлементного анализа гаденских цирконов установлено, что их материнские породы, преимущественно кислого состава, скорее всего, граниты, выплавляемые в «холодных» $\left(700-800{ }^{\circ} \mathrm{C}\right)$ условиях. Сами гаденские литофильные породы подвергались выветриванию вблизи земной поверхности. Продолжение формирования цирконов в этих породах указывает на захоронение первичных пород глубоко в мантии, что свидетельствует о геодинамической активности Земли в Гадее. Очевидно, основным механизмом активности была тяжелая метеоритная бомбардировка, захватившая как Землю, так и ее спутник - Луну. Именно эти причины вызвали образование больших масс основных пород, поднимающихся из мантии. Дифференциация основных масс служит основанием формирования малых количеств кислых расплавов, в которых и образовались сохранившиеся до наших дней гаденские цирконы.

Конечно, это предварительный, плохо доказуемый сценарий формирования коры гаденского возраста. Безусловно, только дальнейшие исследования древнейших пород и их минералов позволят нам понять природу геологических процессов Гаденского эона.

Выполнение данных исследований стало возможным благодаря поддержке интеграционного проекта № 87 СО РАН и проекта РФФИ № 13-05-12026 офи_м.

\section{4. ЛИTEPATУPA / REFERENCES}

Allègre C.J., Poirier J.P., Humler E., Hofmann A.W., 1995. The Chemical-Composition of the Earth. Earth and Planetary Science Letters 134 (3-4), 515-526. http://dx.doi.org/10.1016/0012-821X(95)00123-T.

Binder A.B., 1982. The Moon: Its figure and orbital evolution. Geophysical Research Letters 9 (1), 33-36. http://dx.doi.org/ 10.1029/GL009i001p00033.

Blichert-Toft J., Albarède F., 2008. Hafnium isotopes in Jack Hills zircons and the formation of the Hadean crust. Earth and Planetary Science Letters 265 (3-4), 686-702. http://dx.doi.org/10.1016/j.epsl.2007.10.054.

Compston W., Pidgeon R.T., 1986. Jack Hills, evidence of more very old detrital zircons in Western-Australia. Nature 321 (6072), 766-769. http://dx.doi.org/10.1038/321766a0.

Dziewonski A.M. 1984. Mapping the lower mantle, determination of lateral heterogeneity up to degree and order 6. Journal of Geophysical Research 89 (B7), 5929-5952. http://dx.doi.org/10.1029/JB089iB07p05929.

Glukhovskii M.Z., Kuz'min M.I., 2013. The Kotuikan ring structure as possible evidence for a large impact event in the northern Siberian craton. Russian Geology and Geophysics 54 (1), 1-19. http://dx.doi.org/10.1016/j.rgg.2012.12.001.

Glukhovsky M.Z., Moralev V.M., Kuz'min M.I., 1994. The hot belt of the early Earth and its evolution. Geotektonika (Russian Geotectonics) (5), 3-15 (in Russian) [Глуховский М.3., Моралев В.М., Кузьмин М.И. Горячий пояс ранней Земли и его эволюция // Геотектоника. 1994. № 5. С. 3-15]. 
Goldblatt C., Zahnle K.J., Sleep N.H., Nisbet E.G., 2010. The Eons of Chaos and Hades. Solid Earth 1 (1), 1-3. http://dx. doi.org/10.5194/se-1-1-2010.

Grange M.L., Pidgeon R.T., Nemchin A.A., Timms N.E., Meyer C., 2013. Interpreting the U-Pb data from primary and secondary features in lunar zircon. Geochimica et Cosmochimica Acta 101, 112-132. http://dx.doi.org/10.1016/j.gca. 2012.10.013.

Harrison T.M., Schmitt A.K., McCulloch M.T., Lovera O.M., 2008. Early (N = 4.5 Ga) formation of terrestrial crust: Lu-Hf, delta O-18, and Ti thermometry results for Hadean zircons. Earth and Planetary Science Letters 268 (3-4), 476-486. http://dx.doi.org/10.1016/j.epsl.2008.02.011.

Holden P., Lanc P., Ireland T.R., Harrison T.M., Foster J.J., Bruce Z., 2009. Mass-Spectrometric Mining of Hadean Zircons by Automated SHRIMP Multi-Collector and Single-Collector U/Pb Zircon Age Dating: The First 100,000 grains. International Journal of Mass Spectrometry 286 (2-3), 53-63. http://dx.doi.org/10.1016/j.ijms.2009.06.007.

Khain V.E., 2003. Main Problems of Modern Geology. Nauchny Mir, Moscow, 348 p. (in Russian) [Хаин B.E. Основные проблемы современной геологии. М.: Научный мир, 2003. 348 с.].

Kinny P., Wijbrans J.R., Froude D.O., Williams I.S., Compston W., 1990. Age constraints on the geological evolution of the Narryer Gneiss Complex, Western Australia. Australian Journal of Earth Sciences 37 (1), 51-69. http://dx.doi.org/ 10.1080/08120099008727905.

Kuzmin M.I., Yarmolyuk V.V., Kravchinsky V.A., 2010. Phanerozoic hot spot traces and paleogeographic reconstructions of the Siberian continent based on interaction with the African large low shear velocity province. Earth-Science Reviews 102 (1-2), 29-59. http://dx.doi.org/10.1016/j.earscirev.2010.06.004.

Lauretta D., 2011. A cosmochemical view of the Solar System. Elements 7 (1), 11-16. http://dx.doi.org/10.2113/ gselements.7.1.11.

Maas R., Kinny P.D., Williams I.S., Froude D.O., Compston W., 1992. The Earths oldest known crust - a geochronological and geochemical study of 3900-4200 Ma old detrital zircons from Mt. Narryer and Jack Hills, Western Australia. Geochimica et Cosmochimica Acta 56 (3), 1281-1300. http://dx.doi.org/10.1016/0016-7037(92)90062-N.

Maruyama S., Kumazawa M., Kawakati S., 1994. Towards a new paradigm on the Earth's dynamics. The Journal of the Geological Society of Japan 100, 1-3.

Maruyama S., Santosh M., Zhao D., 2007. Superplume, supercontinent, and postperovskite: mantle dynamics and anti-plate tectonics on the core-mantle boundary. Gondwana Research 11 (1-2), 7-37. http://dx.doi.org/10.1016/j.gr.2006.06.003.

McDonough W.G., Sun S.S., 1995. The composition of the Earth. Chemical Geology 120 (3-4), 223-253. http://dx.doi.org/ 10.1016/0009-2541(94)00140-4.

Menneken M., Nemchin A.A., Geisler T., Pidgeon R.T., Wilde S.A., 2007. Hadean diamonds in zircon from Jack Hills, Western Australia. Nature 448 (7156), 917-920. http://dx.doi.org/10.1038/nature06083.

Myers J.S., 1988. Early Archean Narryer gneiss complex, Yilgarn Craton, Western-Australia. Precambrian Research 38 (4), 297-307. http://dx.doi.org/10.1016/0301-9268(88)90029-0.

Nebel O., Rapp R.P., Yaxley G.M., 2014. The role of detrital zircons in Hadean crustal research. Lithos 190-191, 313-327. http://dx.doi.org/10.1016/j.lithos.2013.12.010.

Nebel-Jacobsen Y., Münker C., Nebel O., Gerdes A., Mezger K., Nelson D.R., 2010. Reworking of Earth's first crust: constraints from Hf isotopes in Archean zircons from Mt. Narryer, Australia. Precambrian Research 182 (3), 175-186. http://dx.doi.org/10.1016/j.precamres.2010.07.002.

O’Neil J., Boyet M., Carlson R.W., Paquette J.-L., 2013. Half a billion years of reworking of Hadean mafic crust to produce the Nuvvuagittuq Eoarchean felsic crust. Earth and Planetary Science Letters 379, 13-25. http://dx.doi.org/10.1016/ j.epsl.2013.07.030.

Taylor D.J., McKeegan K.D., Harrison T.M., 2009. Lu-Hf zircon evidence for rapid lunar differentiation. Earth and Planetary Science Letters 279 (3-4), 157-164. http://dx.doi.org/10.1016/j.epsl.2008.12.030.

Wood B., 2011. The formation and differentiation of Earth. Physics Today 64 (12), 40-45 http://dx.doi.org/10.1063/ PT.3.1362.

Wood B.J., Halliday A.N., 2010. The lead isotopic age of the Earth can be explained by core formation alone. Nature 465 (7299), 767-771. http://dx.doi.org/10.1038/nature09072.

Wood B.J., Walter M.J., Wade J., 2006. Accretion of the Earth and segregation of its core. Nature 441 (7095), 825-833. http://dx.doi.org/10.1038/nature04763.

Yarmolyuk V.V., Kuzmin M.I., 2012. Late Paleozoic and Early Mesozoic rare-metal magmatism of Central Asia: Stages, provinces, and formation settings. Geology of Ore Deposits 54 (5), 313-333. http://dx.doi.org/10.1134/S1075701512050054.

Zhao, D., 2001. Seismic structure and origin of hotspots and mantle plumes. Earth and Planetary Science Letters 192 (3), 251-265. http://dx.doi.org/10.1016/S0012-821X(01)00465-4.

Zharkov V.N., 2000. On the history of the lunar orbit. Solar System Research 34 (1), 1-11. 
M.I. Kuz'min: The Precambrian history of the origin and evolution of the Solar System and Earth...

Zonenshain L.P., Kuz'min M.I., 1983. Intraplate volcanism and its significance for the understanding of processes in the Earth's mantle. Geotektonika (Russian Geotectonics) (1), 28-45 (in Russian) [Зоненшайн Л.П., Кузьмин М.И. Внутриплитовый вулканизм и его значение для понимания процессов в мантии Земли // Геотектоника. 1983. № 1. C. 28-45].

Zonenshain L.P., Kuz'min M.I., Moralev V.M., 1976. Global tectonics, magmatism and metallogeny. Nedra, Moscow, 231 p. (in Russain) [Зоненшайн Л.П., Кузьмин М.И., Моралев В.М. Глобальная тектоника, магматизм и металлогения. М.: Недра, 1976. 231 с.].

Zonenshain L.P., Kuz'min M.I., Natapov L.M., 1990. Plate Tectonics of the USSR Territory. Nedra, Moscow, V. 1, 326 p.; V. 2, 334 p. (in Russian) [Зоненшайн Л.Р., Кузьмин М.И., Натапов Л.М. Тектоника литосферных плит территории СССР. М.: Недра, 1990. Кн. 1, 326 с. Кн. 2, 334 с.].

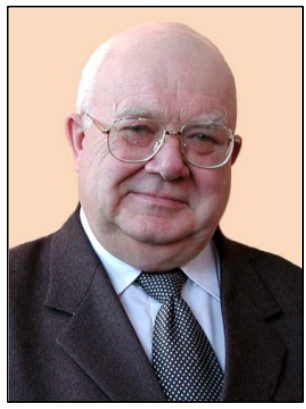

Кузьмин Михаил Иванович, докт. геол.-мин. наук, академик РАН

Институт геохимии им. А.П. Виноградова СО РАН

664033, Иркутск, ул. Фаворского, 1А, Россия

Тел.: (3952)426500; \ e-mail: mikuzmin@igc.irk.ru

Kuz'min, Mikhail I., Doctor of Geology and Mineralogy, Academician of RAS

A.P. Vinogradov Institute of Geochemistry of SB RAS

1A Favorsky street, Irkutsk 664033, Russia

Tel.: (3952)426500; $₫$ e-mail: mikuzmin@igc.irk.ru 